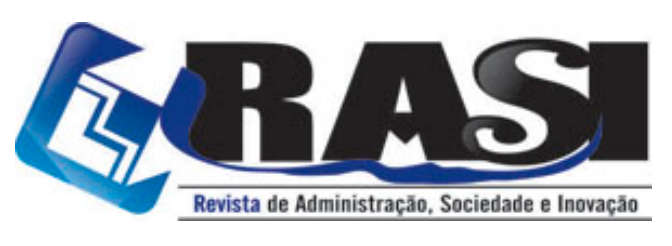

http://www.rasi.vr.uff.br

RASI, Volta Redonda/RJ, v. 7, n. 2, pp. 07-28, Mai./Ago. 2021

\title{
A Hélice Tríplice na produção do ecossistema de empreendedorismo do IFRJ - Campus Engenheiro Paulo de Frontin.
}

Juliano dos Santos Moreira (UFRRJ) - julianodsmoreira@gmail.com

Thiago Borges Renault (UFRRJ) - thiagorenault@ufrrj.br

\begin{abstract}
Resumo:
A sociedade baseada no conhecimento exige das Instituições de Ensino novos desafios ao passo que surgem como agentes de mudanças, fazendo com que a academia seja protagonista do desenvolvimento econômico, social e tecnológico. O presente estudo buscou analisar aspectos que envolvem o surgimento do ambiente de empreendedorismo tecnológico em uma localidade rural e sua relação com as ações de fomento ao empreendedorismo acadêmico promovidas no IFRJ - Campus Engenheiro Paulo de Frontin. Este caracterizou-se como um estudo de caso exploratório qualitativo, com métodos múltiplos de coleta de dados analisados por meio da análise de conteúdo. Observou-se no Campus mobilização estratégica partindo do modelo acadêmico tradicional para o modelo da universidade empreendedora proposto pela abordagem da Hélice Tríplice. Resultados obtidos permitiram a categorização das ações de fomento ao empreendedorismo acadêmico realizadas pelo Campus, capazes de promover um ethos empreendedor que levou à criação de grupos de desenvolvedores e startups no meio acadêmico estudado. Esses atores iniciam uma rede de relacionamentos externos ao Campus, que resultam em um ecossistema de empreendedorismo ainda incipiente na localidade. $\mathrm{O}$ estudo possibilitou a descrição do ecossistema de empreendedorismo tecnológico que emerge em contraste à localidade rural do Campus, apresentando pontos fortes e necessidades de melhorias deste ecossistema.

Palavras-chave: Hélice tríplice; universidade empreendedora; ecossistemas de empreendedorismo, empreendedorismo.

\section{The Triple Helix promoting the IFRJ - Campus Engenheiro Paulode Frontin - Entrepreneural Ecosystem.}

\begin{abstract}
:
Knowledge-based Society demands new challenges for Educational Institutions whereas they emerge as change agents, making the Academy rise as a leading figure for economic, social and technological development. The present study aimed to analyze aspects regarding the rise of the technological entrepreneurial environment at a rural location and its relationship with academic entrepreneurship fomenting activities promoted by IFRJ Campus Engenheiro Paulo de Frontin. The research is defined as an exploratory, qualitative case study with multiple data collect methods analyzed through the content analysis method. It was observed in the Campus a strategic move from the traditional academic model towards the entrepreneurial university model, proposed by the Triple Helix Model. Results allowed an academic entrepreneurship fomenting actions categorization, performed by the Campus, capable to promote an entrepreneurial Ethos that led to the creation of developing groups and startups in the studied academic environment. These actors start an external relationship net, that results in an incipient entrepreneurial ecosystem in its location. The study made possible the technological entrepreneurial ecosystem's description that emerges in contrast to the rural characteristics of the Campus' location, presenting the ecosystem's strengths and improvement needs.
\end{abstract}

Keywords: Triple helix; entrepreneurial university; entrepreneurial ecosystems, entrepreneurship.

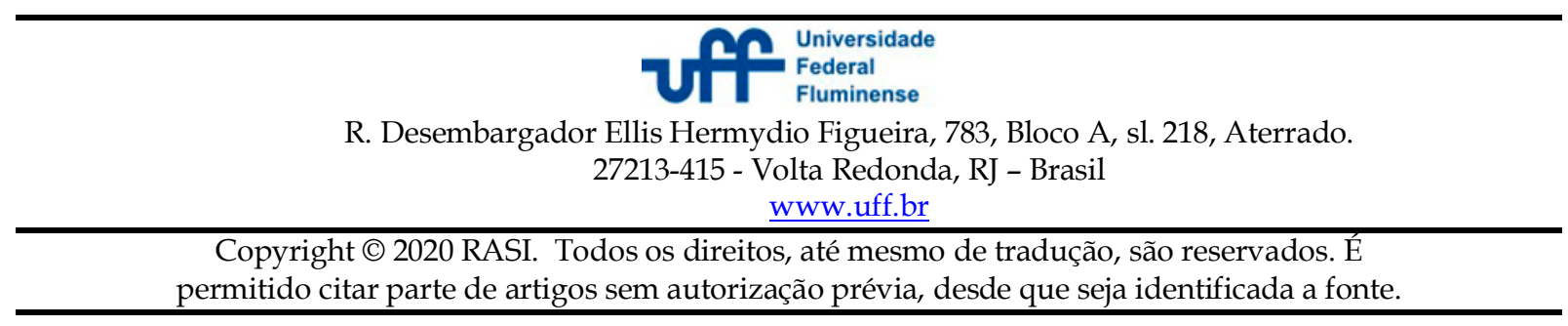




\section{A Hélice Tríplice na produção do ecossistema de empreendedorismo do IFRJ - Campus Engenheiro Paulo de Frontin.}

\section{Introdução}

Historicamente, é notório o papel da academia na geração e disseminação do conhecimento. A nova dinâmica econômica, social e tecnológica faz com que o modelo tradicional de fluxo linear de conhecimento alcance o esgotamento. Tal contexto demanda dessas instituições uma postura cada vez mais orientada ao ambiente externo na busca pela promoção do desenvolvimento sustentável, emergindo como agentes promotores de mudanças em seu meio de atuação. Desta forma, faz-se com que o conhecimento ultrapasse os muros da academia rumo à sociedade. Ao assumirem esse novo papel de protagonista, as instituições de ensino promovem inúmeras ações antes predominantemente exclusivas de atores pertencentes à indústria e ao poder público, por exemplo. Assim, a presente pesquisa teve como objetivo a análise de uma Instituição Pública Federal de Ensino cujas ações rumo à postura empreendedora têm gerado resultados passíveis de serem explorados mais detalhadamente, buscando responder ao seguinte problema de pesquisa: Qual a relação entre as ações de fomento ao empreendedorismo promovidas pelo CEPF e o ambiente de empreendedorismo tecnológico que emerge na localidade?

Desta forma, verificou-se a relação entre os atores que emergem das ações da instituição e o surgimento de um ecossistema de empreendedorismo, ainda incipiente, na localidade.

\section{Referencial teórico}

As mudanças ocorridas no mundo a partir do final do século $\mathrm{XX}$, tais com a globalização, a popularização da internet, os avanços da informática e incorporação de novas tecnologias no cotidiano, fazem com que o conhecimento tenha papel central na sociedade. Ao tratar dessa nova realidade, observam-se três esferas principais cujos relacionamentos merecem atenção quando partimos para uma análise das dinâmicas sociais, econômicas e tecnológicas Universidade, Indústria (empresas privadas) e Governo (Etzkowitz, \& Zhou, 2017). A Hélice Tríplice é um modelo de análise da relação entre as três principais esferas institucionais da sociedade (relação Universidade-Indústria-Governo), este modelo propõe uma nova dinâmica de relacionamento orientada ao desenvolvimento por meio da inovação e empreendedorismo na busca por solução de problemas e potencialidades da localidade (Etzkowitz, \& Zhou, 2017).

O modelo demanda que as Universidades assumam uma "terceira missão" - a promoção do desenvolvimento econômico - além de suas atividades tradicionais de ensino e pesquisa (Etzkowitz, \& Zhou, 2017; Etzkowitz, \& Leydesdorff, 2000; Silva, Ribeiro, \& Barros, 2019; Ramos, et al., 2017). Dentro deste contexto, o modelo da Hélice Tríplice apresenta dinâmicas de interação formais e informais de longa duração, onde cada ator das três esferas mantém seu papel primário, porém, em algum momento, exercem papéis dos demais atores da Hélice (Etzkowitz, \& Zhou, 2017, Díez-Vial, \& Montoro-Sánches, 2016). A Figura 1 apresenta as hélices em sua dinâmica em espirais de macrocirculações [MaC] (ao longo das hélices) e microcirculações $[\mathrm{MiC}]$ (dentro de uma esfera em particular), como também suas relações de independência e interdependência, conflitos e confluência de interesses, conforme aponta Etzkowitz (2008). O modelo da Hélice Tríplice introduz uma nova ordem social sancionada pelas três esferas, demandando mudanças institucionais de inovação e redefinição das relações de cooperação e benefícios entre as mesmas, o que fortalece a interdependência entre as 
instituições do sistema (Sarpong, Abdrazak, \& Meissner, 2017; Damnjanovic, Jovanovic, \& Rakicevic, 2019).

De acordo com Etzkowitz (2008), as macrocirculações são capazes de promover um sistema que integra atores das três esferas do modelo. Por outro lado, as microcirculações, ainda segundo Etzkowitz (2008), são capazes de potencializar internamente as hélices em um nível individual.

Figura 1 - Dinâmica das macro e microcirculações da Hélice Tríplice.

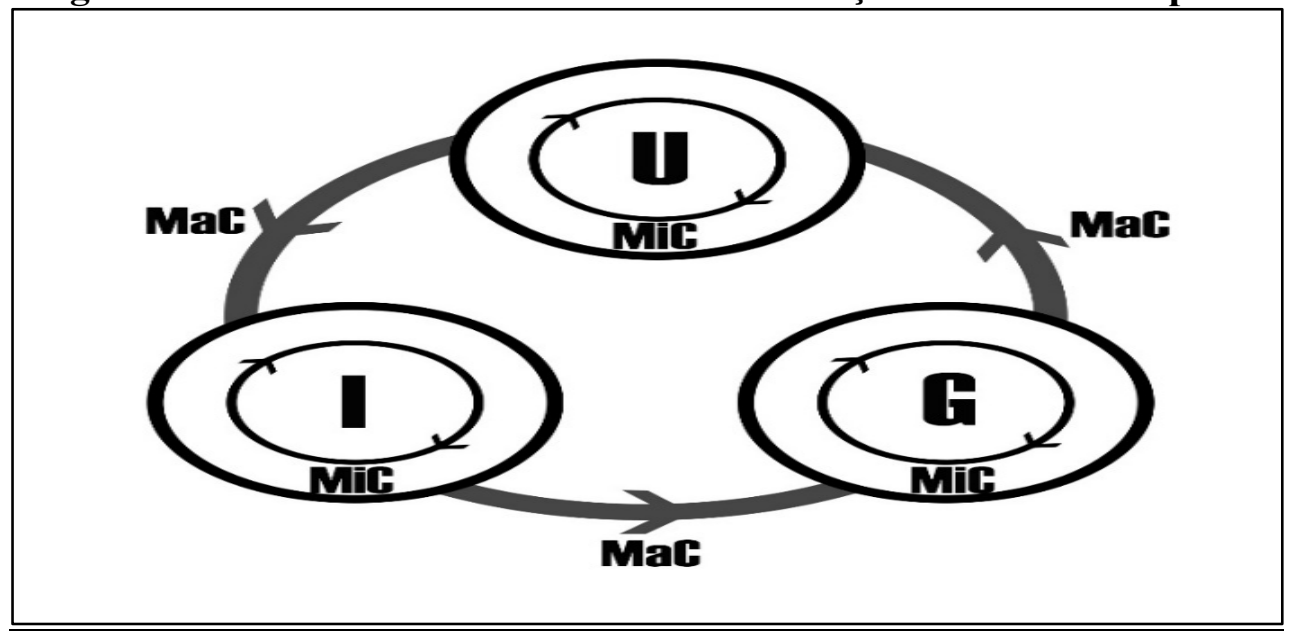

Fonte: Adaptado de Etzkowitz (2008).

Dentro do modelo proposto, a universidade possui papel de instituição quintessencial na promoção de um fluxo de expertise, estímulo à hibridização entre esferas sociais, bem como na invenção e inovação de novos formatos sociais (Etzkowitz, 2008). No Brasil, diversos estudos tratam do empreendedorismo acadêmico por meio da criação de startups de docentes e discentes e fomento ao empreendedorismo (Rosa, 2014; Renault, et al., 2010; Chais, et al., 2019; Alves, Fischer, \& Schaeffer, 2019; Bueno 2017) que destacam o papel da universidade na geração de riqueza dentro da proposta apresentada pela Hélice Tríplice.

Desta maneira, a Universidade representa o princípio gerador das sociedades fundadas no conhecimento, sendo fundamentais na inovação industrial, no desenvolvimento econômico e na renovação de conhecimentos profissionais via programas de gestão e negócios (Etzkowitz, 2008; Lundvall, 2016; Santos, \& Benneworth, 2019). Diante da proposta da Hélice Tríplice, as universidades surgem como responsáveis pela capitalização do conhecimento, bem como um motor da economia baseada no conhecimento (Etzkowitz, 2008; Etzkowitz, \& Zhou, 2017).

A universidade moderna é o resultado de duas revoluções acadêmicas ocorridas no século XIX e XX que resultam no modelo da Hélice Tríplice e de uma sociedade baseada no conhecimento, onde a Academia assume para si a missão de desenvolvimento econômico e social questionando o tradicional modelo "torre de marfim" (Etzkowitz, \& Leydesdorff, 1997).

Ao assumir seu papel no modelo da Hélice Tríplice, a universidade desenvolve inúmeras ações com o objetivo de fomentar o empreendedorismo e a inovação ao passo que desenvolvem parcerias estratégicas e oferecem serviços de consultorias (Damnjanovic, et al., 2019). Um dos exemplos do papel das Instituições de Ensino no fomento ao empreendedorismo e inovação são as incubadoras de empresas, apresentadas por Wright, Siegel, \& Mustar (2017) como um ambiente público ou privado, ligado a universidades ou corporações, capazes de auxiliar a estruturar ideias de negócios, identificar investidores e mercados potenciais. 
Observam-se na literatura diversos autores que apresentam resultados de ações desenvolvidas pela academia ao redor do mundo na promoção do empreendedorismo acadêmico. Tais ações buscam o estímulo à cultura empreendedora no meio acadêmico através de atividades curriculares e extracurriculares, networking industrial e criação de instituições e mecanismos para desenvolvimento e transferência de tecnologias oriundas da academia (Miller, \& Acs, 2018; Feld, 2012; Meyer, 2003; Lorentz, 2015).

Ao conceber empresas em seu ambiente, as universidades são capazes de promover a criação de um ambiente de fomento ao empreendedorismo em sua localidade, no qual novos empreendimentos emergem e encontram um ambiente favorável para seu desenvolvimento (Gamonar, Jannuzzi, \& Munaro, 2017). Esses ambientes são denominados ecossistemas de empreendedorismo.

Os Ecossistemas de Empreendedorismo têm sua origem nas analogias entre os ecossistemas biológicos e os empresariais. Ecossistemas empresariais, assim como os biológicos, emergem a partir de uma estrutura simples para uma comunidade mais estruturada e auto-organizada, onde seus agentes coevoluem, por meio de estratégias de cooperação e competição (Moore, 1993; Mitleton-Kelly, 2003). Um ecossistema de negócios exige a interação de múltiplos stakeholders engajados no desenvolvimento de uma rede de relacionamentos de interdependência, buscando relacionamentos capazes de fortalecer cada vez mais internamente essa rede por meio do alcance de seus objetivos (Iansiti, \& Levien, 2004; Acs, Szerb, \& Lloyd, 2017; Van Rijnsoever, 2020).

A Universidade Empreendedora possui papel fundamental dentro desses ecossistemas por meio das incubadoras universitárias, da transferência de tecnologia e de oportunidades para o fomento do empreendedorismo através das startups como novas empresas de inovação (Cantamessa, 2016; Bezanilla, et al., 2017; Siegel, \& Wright, 2015).

Ecossistemas de negócio possuem quatro estágios de evolução, conforme apresentado no quadro 1, dentro dos quais seus atores devem combinar estratégias de cooperação e competição na busca pela liderança desse ecossistema, como destaca Moore (1993): i) nascimento; ii) expansão, iii) liderança; e iv) autorrenovação ou morte, caso a autorrenovação não aconteça.

Para realização de uma análise de ecossistemas de empreendedorismo, dois aspectos principais devem ser considerados: amplitude geográfica e detalhamento da análise do ecossistema (ANDE, 2013). Existem abordagens com características distintas quanto aos dois aspectos citados, ANDE (2013) nos apresenta uma síntese baseada na revisão das principais abordagens para avaliação de ecossistemas de empreendedorismo. 


\section{Quadro 1 - Evolução do ecossistema de negócios.}

\begin{tabular}{|c|l|l|}
\hline Estágio & \multicolumn{1}{|c|}{ Estratégia de Cooperação } & \multicolumn{1}{c|}{ Estratégia de Competição } \\
\hline Nascimento & $\begin{array}{l}\text { Trabalho com consumidores e } \\
\text { fornecedores na definição de novas } \\
\text { propostas de valor sobre a inovação em } \\
\text { seu estágio embrionário. }\end{array}$ & $\begin{array}{l}\text { Proteger as ideias de outros que possam estar } \\
\text { trabalhando na definição de ofertas similares. } \\
\text { Aliar-se a consumidores lideres, fornecedores- } \\
\text { chave e canais importantes. }\end{array}$ \\
\hline \multirow{2}{*}{ Expansão } & $\begin{array}{l}\text { Trazer nova oferta para um mercado } \\
\text { mais amplo por meio de trabalho com } \\
\text { fornecedores e parceiros para aprimorar } \\
\text { o fornecimento e maximizar a cobertura } \\
\text { de mercado. }\end{array}$ & $\begin{array}{l}\text { Derrotar implementações alternativas de } \\
\text { ideias similares. Garantir que sua abordagem é } \\
\text { o padrão do mercado na sua classe através do } \\
\text { domínio de segmentos de mercado. }\end{array}$ \\
\hline $\begin{array}{l}\text { Liderança } \\
\text { que incentive fornecedores e e } \\
\text { consumidores a trabalhar em conjunto } \\
\text { para continuar aprimorando a oferta } \\
\text { completa. }\end{array}$ & $\begin{array}{l}\text { Manutenção de forte poder de barganha na } \\
\text { relação com outros players no ecossistema, } \\
\text { incluindo consumidores-chave e fornecedores } \\
\text { valorizados. }\end{array}$ \\
\hline $\begin{array}{l}\text { Autorrenovação } \\
\text { ou morte }\end{array}$ & $\begin{array}{l}\text { Trabalhar com inovadores para trazer } \\
\text { novas ideias para o ecossistema } \\
\text { existente. }\end{array}$ & $\begin{array}{l}\text { Manutenção de fortes barreirasà entrada para } \\
\text { prevenir que inovadores } \\
\text { ecossistemas alternativos. Manter alto custo } \\
\text { de mudança para o consumidor para ganho de } \\
\text { tempo na incorporação de novas ideias aos } \\
\text { próprios produtos e serviços. }\end{array}$ \\
\hline
\end{tabular}

Fonte: Moore (1993, p. 77).

Dentro da síntese proposta por ANDE (2013), destaca-se a necessidade de realizar a avaliação em três níveis. Esta avaliação inicia-se com identificação da composição do ecossistema, passando pela análise dos resultados e indicadores das ações de atores do ecossistema, finalizando com impactos socioeconômico e tecnológico do mesmo (ANDE, 2013). Esses níveis são apresentados na Figura 2.

- A avaliação dos determinantes é o primeiro nível de avaliação, eles estão ligados aos fatores que afetam o empreendedorismo, dividindo-se em oito determinantes: finanças; apoio aos negócios; política; mercados; capital humano; infraestrutura; P\&D; e cultura;

- O nível de performance empreendedora, se refere aos resultados promovidos pelas atividades dos empreendedores, avaliados por meio de indicadores, tais como: quantidade de empresas formais estabelecidas e de empresas de alto crescimento; quantidade de atores geradores de emprego; e nível de sobrevivência e morte de empresas;

- O terceiro nível de avaliação - impactos - se refere ao valor gerado pelos empreendedores dentro do ecossistema, representados por indicadores macroeconômicos, tais como: crescimento econômico, criação de empregos, e redução da pobreza. 
Figura 2 - Níveis de avaliação do ecossistema empreendedor.

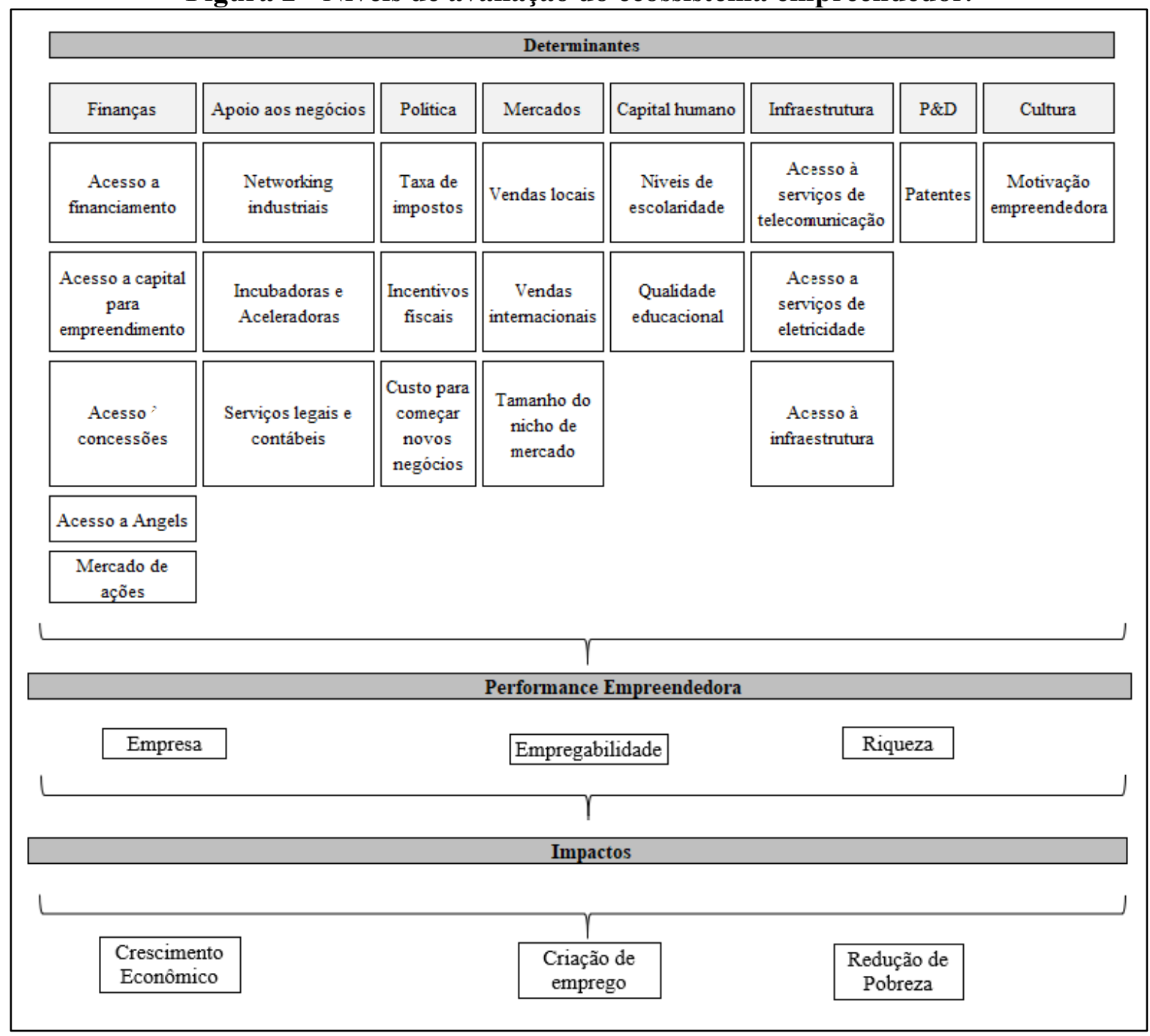

Fonte: ANDE (2013, p. 6)

\section{Procedimento Metodológico}

O estudo caracterizou-se como um estudo de caso exploratório único, no qual existe pouco conhecimento acumulado e sistematizado (Yin, 2005; Vergara, 2014). Estudos de casos surgem para definir a população e são capazes de resultar em informações confiáveis acerca de uma classe mais ampla (Ruddin, 2006). Para o estudo de caso, utilizou-se o processo descrito por Eisenhardt (1989). Assim, inicialmente selecionou-se o caso - baseado nas observações iniciais sobre o contexto de surgimento de desenvolvedores discentes empreendendo na localidade do CEPF e seus relacionamentos com atores externos ao Campus. Em seguida, foram definidos e elaborados os instrumentos de coleta de dados, a saber: pesquisa documental; roteiro semiestruturado de entrevistas e observação participante. Após a elaboração dos roteiros, foi iniciada a fase de realização das entrevistas e a análise dos dados, estas ações foram realizadas de forma paralela para possibilitar ajustes e a triangulação das informações obtidas. Com o início da etapa de análise dos dados, foi possível levantar os aspectos iniciais do fenômeno estudado, o que possibilitou a comparação com a literatura existente. O processo realizado e as etapas do estudo de Eisenhardt (1989) são apresentados no quadro 2. 
Como problema de pesquisa, buscou-se levantar as ações do Campus no fomento ao empreendedorismo acadêmico e sua relação com o ecossistema de empreendedorismo tecnológico, ainda incipiente, que emerge na localidade. Deste modo, a pergunta de pesquisa foi definida como: Qual a relação entre as ações de fomento ao empreendedorismo promovidas pelo CEPF e o ambiente de empreendedorismo tecnológico que emerge na localidade?

Como objetivo final, buscou-se responder as perguntas de pesquisa para analisar o surgimento do ambiente de empreendedorismo tecnológico na localidade rural do CEPF e sua relação com as ações de fomento ao empreendedorismo acadêmico promovidas pelo Campus. Como objetivo intermediário buscou-se: i. Identificação das ações de fomento ao empreendedorismo acadêmico no CEPF; ii. Identificação das interações e aspectos da Hélice Tríplice nas relações do CEPF na promoção do empreendedorismo acadêmico; iii. Descrição das características do ambiente de empreendedorismo que surge na localidade do CEPF; iv. Apresentação de pontos fortes e oportunidades de melhorias na estrutura do empreendedorismo na localidade;

Foram realizadas ao todo 25 entrevistas, conforme quadro 3 e posteriormente tabuladas em planilha no MS Excel onde, ao lado de cada tópico abordado na entrevista, foram inseridas as contribuições do entrevistado.

Quadro 2 - Processo de construção de teorias pelos estudos de caso: comparação com a pesquisa realizada.

\begin{tabular}{|c|c|c|}
\hline Etapa & Atividades sugeridas por Eisenhardt (1989) & Realizado \\
\hline Iniciando & $\begin{array}{l}\text { Definição da pergunta de pesquisa, possíveis } \\
\text { construtos prévios. }\end{array}$ & Definição de pergunta de pesquisa. \\
\hline \multirow{2}{*}{$\begin{array}{l}\text { Selecionando } \\
\text { casos }\end{array}$} & Especificação da população. & Definição da população. \\
\hline & Amostras teóricas, não aleatórias. & Definição dos sujeitos. \\
\hline \multirow{2}{*}{$\begin{array}{c}\text { Elaborando } \\
\text { instrumentos e } \\
\text { protocolos }\end{array}$} & Métodos múltiplos de coleta de dados. & $\begin{array}{l}\text { Observação participante, pesquisa } \\
\text { documental e entrevistas. }\end{array}$ \\
\hline & Dados quantitativos e qualitativos. & $\begin{array}{l}\text { Dados } \\
\text { qualitativos. }\end{array}$ \\
\hline \multirow[b]{2}{*}{$\begin{array}{l}\text { Entrando ao } \\
\text { campo }\end{array}$} & Sobreposição de coleta e análise de dados. & Coleta e análise de dados. \\
\hline & Métodos flexíveis e oportunistas de coleta. & $\begin{array}{l}\text { Roteiro semiestruturado } \\
\text { observação participante. }\end{array}$ \\
\hline \multirow[b]{2}{*}{ Analisando dados } & Análise interna do caso. & Aplicação das entrevistas. \\
\hline & $\begin{array}{l}\text { Análise cruzada dos dados na busca por padrões, } \\
\text { usando diferentes técnicas. }\end{array}$ & $\begin{array}{l}\text { Análise das entrevistas } \mathrm{e} \\
\text { triangulação das informações. }\end{array}$ \\
\hline \multirow{2}{*}{$\begin{array}{l}\text { Construindo } \\
\text { hipóteses }\end{array}$} & $\begin{array}{l}\text { Tabulação literária das evidências para cada } \\
\text { construto. }\end{array}$ & Tabulação das entrevistas. \\
\hline & $\begin{array}{l}\text { Buscar evidências dos "porquês" por trás das } \\
\text { relações. }\end{array}$ & Consolidação dos resultados. \\
\hline \multirow{2}{*}{ Analisar literatura } & Comparação com literatura conflitante. & $\begin{array}{l}\text { Comparação com literatura } \\
\text { conflitante. }\end{array}$ \\
\hline & Comparação com literatura similar. & Comparação com literatura similar. \\
\hline $\begin{array}{l}\text { Busca por } \\
\text { fechamento }\end{array}$ & Saturação teórica, quando possível. & Fechamento/Conclusões. \\
\hline
\end{tabular}
Fonte: Adaptado Eisenhardt (1989).

Para uma análise direcionada desse ambiente de empreendedorismo foram utilizados como modelo de referência os determinantes do framework para avaliação de primeiro nível de ecossistemas de empreendedorismo elaborado por ANDE (2013). O framework possibilitou a categorização das informações obtidas, permitindo uma descrição estruturada das informações sobre o ecossistema em formação. Não houve no estudo o objetivo de realizar a análise do ecossistema local por meio da metodologia sugerida pelo framework, mas, sim, a utilização dos 
determinantes do framework como modelo de categorização para análise, apresentação e explanação dos resultados da pesquisa.

\section{Quadro 3 - Sujeitos entrevistados}

\begin{tabular}{|l|c|}
\hline \multicolumn{1}{|c|}{ Entrevistados } & Identificação HT \\
\hline 15 membros de startups e desenvolvedores discentes matriculados no CEPF. & Indústria \\
\hline $\begin{array}{l}\text { Fundador do BP Instituto - Instituição de treinamento, mentoria e coaching e } \\
\text { Coordenador do Rio Info na área de óleo e gás. }\end{array}$ & Indústria \\
\hline Coordenadora Geral do Centro Técnico Audiovisual. & Governo \\
\hline Gerente Regional do SEBRAE - Sul Fluminense - Três Rios/RJ. & Indústria \\
\hline $\begin{array}{l}\text { Presidente do RING - Coletivo das startups de jogos digitais do estado do Rio de } \\
\text { Janeiro. }\end{array}$ & Indústria \\
\hline $\begin{array}{l}\text { Secretário de Desenvolvimento Econômico e Social do Município de Engenheiro } \\
\text { Paulo de Frontin. }\end{array}$ & Governo \\
\hline Coordenador de Pesquisa e Inovação do CEPF. & Universidade \\
\hline Coordenadora do Núcleo de Produção Digital e Incubadora - CEPF. & Universidade \\
\hline Diretor Geral do CEPF. & Universidade \\
\hline Pró-reitor da Pró-reitoria Adjunta de Pesquisa, pós-graduação e Inovação da IFRJ. & Universidade \\
\hline $\begin{array}{l}\text { Assessor da diretoria de Tecnologia da FAPERJ, Coordenador do programa Startup } \\
\text { Rio - FAPERJ/SECTIDS e Consultor da RIO SOFT. }\end{array}$ & Governo \\
\hline
\end{tabular}

Fonte: Elaborado pelo autor (2020).

Quanto aos demais níveis, não foram identificados dados para definição dos indicadores devido a questões diretamente ligadas à incipiência do ecossistema emergente, tais como:

- A não comercialização dos produtos via mercado consumidor;

- A não formalização das startups existentes e ausência de vínculos formais entre elas e os desenvolvedores;

- Inexistência de estudos anteriores que permitam avaliar o estado anterior à criação das primeiras startups do Campus para avaliação dos impactos promovidos por elas na economia local.

\section{Resultados e Análises}

Os resultados obtidos ao longo da pesquisa foram capazes de apresentar a relação entre as ações de fomento ao empreendedorismo acadêmico no Campus e a emergência de um ambiente de empreendedorismo tecnológico inda incipiente na localidade do Campus.

\subsection{O Campus como universidade empreendedora}

$\mathrm{Na}$ instituição estudada, foram observados aspectos da universidade empreendedora propostos por Etzkowitz (2008), por meio das ações realizadas pelo CEPF com o intuito de fomentar o empreendedorismo acadêmico. Tais ações resultaram na emergência de grupos de desenvolvedores de jogos digitais e produtos tecnológicos com potencial para surgimento de empresas na área de tecnologia. Dentro destes grupos emergentes observa-se a predominância de discentes do CEPF desenvolvendo produtos dentro do Campus.

As ações de fomento ao empreendedorismo promovidas pelo Campus vão ao encontro de pesquisas desenvolvidas por Rosa (2014); Renault et al. (2010); Chais et al., (2019); Alves et al. (2019); Bueno (2017); Miller e Acs (2018); Feld (2012); Meyer (2003); Lorentz (2015). Esses autores apresentam diversas ações promovidas pela academia, no Brasil e ao redor do mundo, que se tornam referência na promoção do desenvolvimento regional. Entre as ações promovidas por essas instituições estão atividades curriculares e extracurriculares que 
estimulam o empreendedorismo acadêmico e resultam em inovação tecnológica e criação de ecossistemas de empreendedorismo e inovação.

As ações que mereceram destaque pelos entrevistados puderam ser classificadas como de caráter pedagógico e não pedagógico de fomento ao empreendedorismo acadêmico nas suas diversas áreas. No nível de distinção entre seu cerne, as ações realizadas pelo Campus no fomento ao empreendedorismo acadêmico foram classificadas em: i) Ações pedagógicas de fomento ao empreendedorismo acadêmico; ii) Ações não-pedagógicas de fomento ao empreendedorismo acadêmico. Conforme apresentado na Figura 3.

Figura 3 - Ações de fomento ao empreendedorismo acadêmico promovidas pelo CEPF.

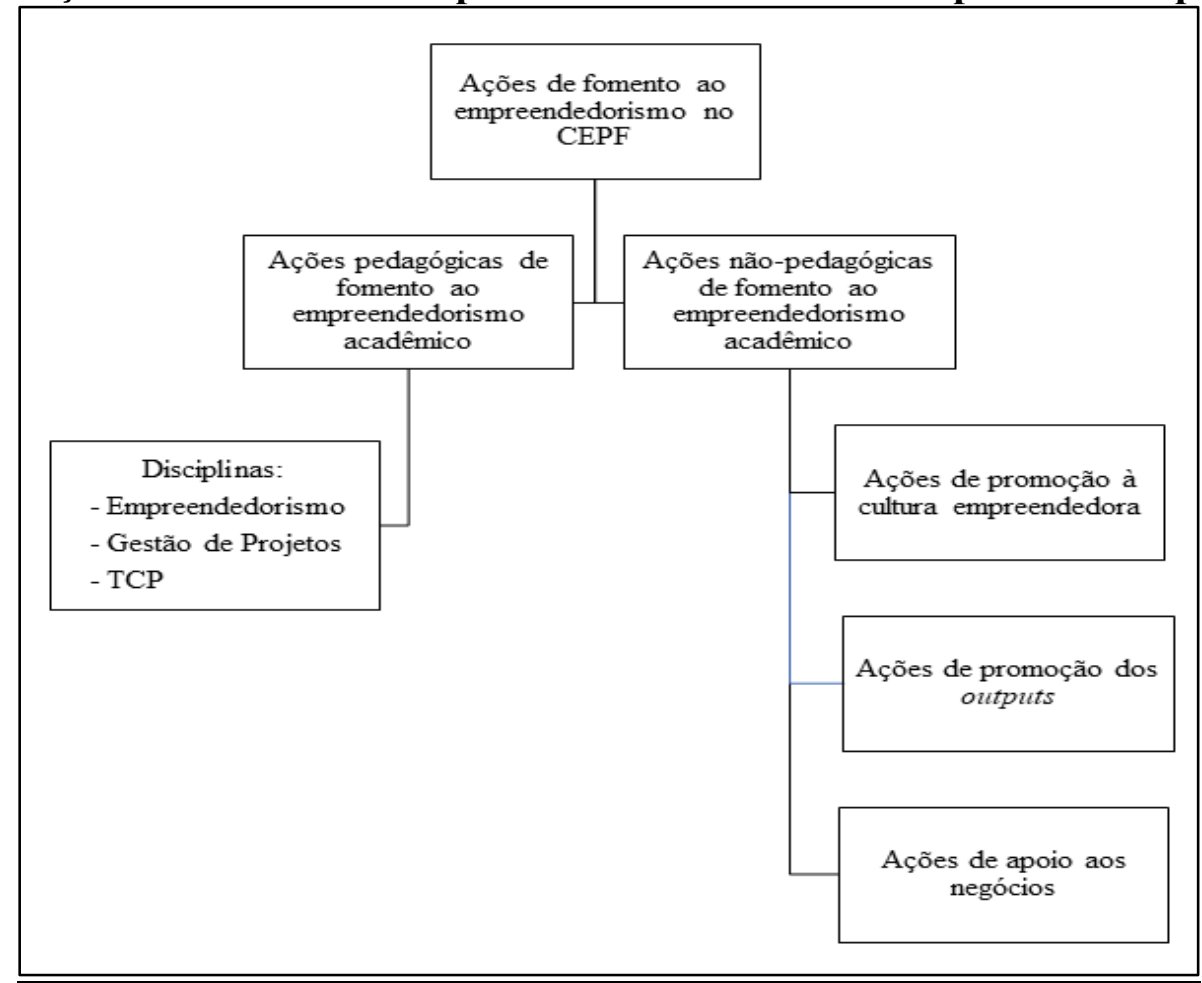

Fonte: Elaborado pelo autor (2020).

As ações pedagógicas de fomento ao empreendedorismo acadêmico são aquelas desenvolvidas dentro de sala de aula, baseadas na grade curricular dos cursos existentes no Campus, observaram-se três destaques identificados como eficazes no fomento ao empreendedorismo acadêmico pelos discentes: disciplina de empreendedorismo; disciplinas de gestão de projetos; e trabalho de conclusão de período (TCP).

Por outro lado, as ações não-pedagógicas de fomento ao empreendedorismo acadêmico não estão diretamente vinculadas à atividades dentro de sala de aula. Essas atividades são promovidas dentro ou fora do Campus para o fomento ao empreendedorismo acadêmico. As ações levantadas junto aos discentes puderam ser divididas em três categorias: i) ações nãopedagógicas de promoção à cultura empreendedora ii) ações não-pedagógicas de promoção dos outputs do empreendedorismo acadêmico e iii) Ações não-pedagógicas de apoio aos negócios.

As ações pedagógicas de fomento ao empreendedorismo foram destacadas pelos entrevistados discentes como eficazes no incentivo à criação de empreendimentos no curso de graduação em jogos digitais, bem como no curso técnico em informática para internet. Dentre essas ações, estão disciplinas cujo foco é o desenvolvimento de conhecimentos e competências 
gerenciais tais como: i) Disciplinas de empreendedorismo; ii) Disciplinas de Gestão de Projetos e; iii) Trabalho de conclusão de período (TCP).

A disciplina de empreendedorismo possui como objetivo propiciar conhecimentos para criação de um negócio aos discentes. Com o conteúdo ministrado, os discentes aprendem a desenvolver um plano de negócios baseado no modelo CANVAS e têm acesso a conhecimentos que os auxiliam na avaliação de oportunidades de mercado e trâmites para criação de uma empresa.

Por outro lado, as disciplinas de gestão de projetos são ministradas com base no Guia PMBOK e possuem como objetivo disponibilizar o conhecimento básico da área de projetos, uma vez que nem todos os alunos que ingressam no curso possuem domínio dos conceitos básicos da área.

Ainda na graduação, ao final de cada semestre letivo, como critério de aprovação no período, os alunos devem elaborar um projeto em grupo. O TCP consiste em uma atividade multidisciplinar na qual os alunos devem se dividir em equipes para desenvolver um jogo baseado nos conteúdos adquiridos ao longo do semestre letivo, por exemplo: jogo em 2D, jogo em 3D, jogo para dispositivos móveis, jogo para plataforma multiplayer, dentre outros. $\mathrm{O}$ desenvolvimento do TCP possui uma dinâmica criada para simular uma empresa e uma apresentação final, semelhante a um pitching. Essa apresentação é realizada para uma banca composta por docentes da área de computação e jogos, bem como eventuais convidados externos ao Campus do meio acadêmico ou do mercado

As ações não-pedagógicas de fomento ao empreendedorismo puderam ser divididas em três categorias que formam uma tríade: i) ações de fomento à cultura empreendedora; ii) ações de promoção de outputs desenvolvidos no CEPF; iii) ações de apoio aos negócios. A Figura 4 ilustra as três categorias observadas nas ações não-pedagógicas de fomento ao empreendedorismo acadêmico no CEPF.

Figura 4 - Ações não-pedagógicas de fomento ao empreendedorismo no CEPF.

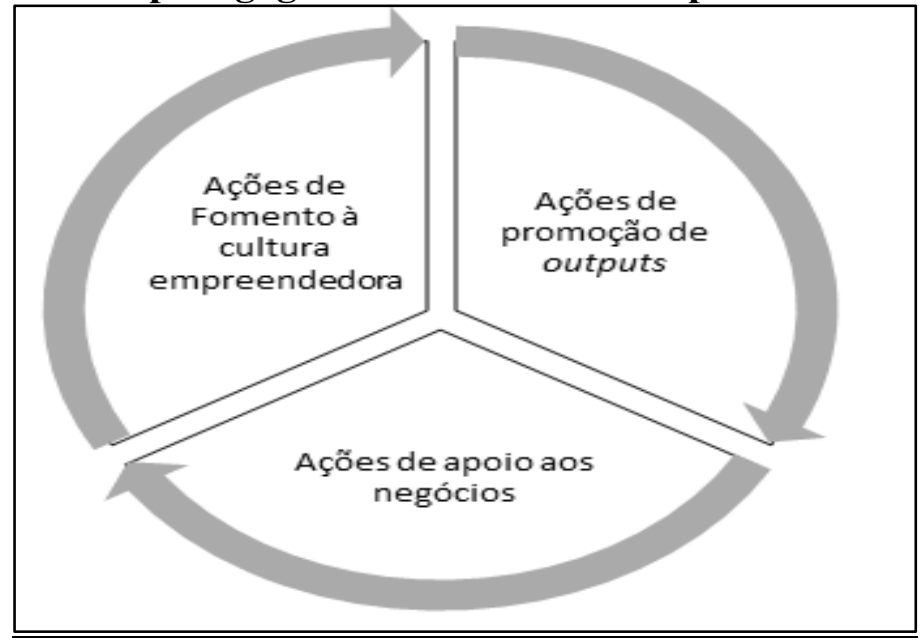

Fonte: Elaborado pelo autor (2020)

Verificou-se uma série de ações do Campus no fomento à participação da comunidade acadêmica em eventos voltados para o fomento à cultura empreendedora. Essas ações possuem como objetivo motivar e incentivar a criatividade direcionada à solução de problemas e criação de produtos. Ainda como atividades não-pedagógicas de fomento ao empreendedorismo, estão ações de promoção dos outputs desenvolvidos no CEPF por meio da exposição de produtos, serviços e ações voltadas ao empreendedorismo desenvolvidos no Campus. 
Por último, temos as ações que buscam dar suporte aos produtos e negócios criados pelos desenvolvedores do Campus por meio da disponibilização de infraestrutura física e de serviços para apoio aos negócios, tais como a Silício Fluminense Incubadora de Jogos Digitais e Economia Criativa (SFInJE) e um Núcleo de Produção Digital (NPD).

Quadro 4 - Ações não-pedagógicas de fomento ao empreendedorismo no CEPF.

\begin{tabular}{|c|c|c|c|}
\hline Ação & Tipo de ação & Objetivo & Categorização \\
\hline $\begin{array}{l}\text { Global Game Jam } \\
2016\end{array}$ & $\begin{array}{c}\text { Evento de } \\
\text { desenvolvimento de } \\
\text { jogos }\end{array}$ & $\begin{array}{l}\text { Incentivo à criação de } \\
\text { jogos e negócios }\end{array}$ & \multirow{3}{*}{ Fomento à cultura empreendedora } \\
\hline $\begin{array}{c}\text { Células } \\
\text { empreendedoras } \\
2018 \\
\end{array}$ & $\begin{array}{l}\text { Evento de fomento ao } \\
\text { empreendedorismo }\end{array}$ & $\begin{array}{l}\text { Incentivo à criação de } \\
\text { negócios }\end{array}$ & \\
\hline $\begin{array}{l}\text { Pitching } \\
\text { empreendedor }\end{array}$ & $\begin{array}{c}\text { Evento de fomento ao } \\
\text { empreendedorismo }\end{array}$ & $\begin{array}{l}\text { Incentivo à criação de } \\
\text { negócios }\end{array}$ & \\
\hline $\begin{array}{l}\text { Brasil Game Show } \\
2016\end{array}$ & Evento de exposição & $\begin{array}{c}\text { Exposição de outputs } \\
\text { do empreendedorismo } \\
\text { acadêmico }\end{array}$ & \multirow{5}{*}{ Promoção de outputs } \\
\hline Rock in rio 2017 & Evento de exposição & $\begin{array}{c}\text { Exposição de outputs } \\
\text { do empreendedorismo } \\
\text { acadêmico }\end{array}$ & \\
\hline $\begin{array}{l}\text { Semana Nacional de } \\
\text { Ciência e tecnologia } \\
2018 \\
\end{array}$ & $\begin{array}{l}\text { Evento de exposição e } \\
\text { tecnologia }\end{array}$ & $\begin{array}{c}\text { Exposição de outputs } \\
\text { do empreendedorismo } \\
\text { acadêmico }\end{array}$ & \\
\hline Game XP 2018 & Evento de exposição & $\begin{array}{c}\text { Exposição de outputs } \\
\text { do empreendedorismo } \\
\text { acadêmico }\end{array}$ & \\
\hline $\begin{array}{c}\text { Projeto de } \\
\text { Incubadora Silício } \\
\text { Fluminense } \\
\end{array}$ & $\begin{array}{l}\text { Fornecimento de } \\
\text { apoio aos negócios }\end{array}$ & $\begin{array}{c}\text { Exposição de outputs } \\
\text { do empreendedorismo } \\
\text { acadêmico }\end{array}$ & \\
\hline $\begin{array}{l}\text { Implementação do } \\
\text { Núcleo de produção } \\
\text { Digital }\end{array}$ & $\begin{array}{l}\text { Fornecimento de } \\
\text { apoio a projetos }\end{array}$ & \multirow{2}{*}{$\begin{array}{l}\text { Apoio aos negócios e } \\
\text { fomento ao } \\
\text { empreendedorismo }\end{array}$} & \multirow{2}{*}{ Apoio aos negócios } \\
\hline $\begin{array}{c}\text { Programa de } \\
\text { treinamento e } \\
\text { consultoria gerencial }\end{array}$ & Apoio aos negócios & & \\
\hline
\end{tabular}

Fonte: Elaborado pelo autor (2020).

As ações de fomento ao empreendedorismo acadêmico desempenhadas pelo Campus atuam de forma complementar entre si para o resultado comum de criação de empreendimentos por parte dos discentes da instituição, conforme apresentado no quadro 4, cujo foco são os alunos da graduação em jogos digitais.

Os grupos de desenvolvedores formados no CEPF possuem as mais variadas composições, indo desde desenvolvedores individuais a grupos de até 13 componentes. Os grupos com maior quantidade de membros possuem como produto final o desenvolvimento de jogos, enquanto os de menor quantitativo foco, além de jogos, atuam no desenvolvimento de aplicativos, sites e produtos tecnológicos em áreas variadas. Os grupos com maior quantidade de componentes justificam uma estrutura maior pelo fato de trabalharem em múltiplos projetos concomitantemente.

Ao passo que esses grupos de desenvolvedores surgem e evoluem, seus relacionamentos iniciam um movimento de saída do Campus, relacionando-se também com atores externos à academia. Esse processo resulta em um ambiente com aspectos de um ecossistema de 
empreendedorismo, com características peculiares ao considerarmos a localidade predominantemente rural do Campus.

As ações de fomento realizadas pelo Campus contam com parcerias que potencializam o fomento ao empreendedorismo tecnológico na localidade.

\section{2. O ecossistema de empreendedorismo incipiente do CEPF}

Por meio das entrevistas e da triangulação de informações foi possível verificar aspectos inerentes a um ecossistema de empreendedorismo, ainda incipiente na localidade predominantemente rural na qual o Campus está inserido. Trata-se de um ambiente inclusivo, favorável ao desenvolvimento de startups, composto por stakeholders que se relacionam para o desenvolvimento de ideias e tecnologias inovadoras (Hernández, \& González, 2017; Gamonar, et al., 2017). Além disso, verifica-se um processo de coevolução entre os atores que surgem neste ecossistema, partindo de uma estrutura simples, fechada ao empreendedorismo acadêmico, para uma estrutura mais complexa e organizada que inicia relacionamentos externos ao CEPF (Moore, 1993). Neste contexto observa-se o surgimento de um processo autônomo de organização da comunidade empreendedora local por meio de iniciativas como o Arquipélago e o DevGirls, responsáveis por fortalecer a cultura empreendedora na localidade.

As atividades de empreendedorismo tecnológico da localidade encontram-se centradas nas ações do Campus e na capacidade deste em mobilizar parceiros das demais esferas da relação U-I-G.

Utilizando como referência os determinantes para avaliação de primeiro nível de ecossistemas de empreendedorismo apresentado por ANDE (2013), foi possível apresentar de forma estruturada as características do ecossistema de empreendedorismo que se encontra em estágio inicial de constituição. Não houve no estudo o objetivo de realizar uma análise do ecossistema local por meio da metodologia sugerida pelo framework, mas, sim, a utilização dos determinantes do modelo como categorização e apresentação das características observadas.

Quanto aos demais níveis - performance empreendedora e impactos -, não foram identificados dados para definição dos indicadores devido a questões diretamente ligadas à incipiência do ecossistema emergente, tais como:

- A não comercialização dos produtos via mercado consumidor;

- A não formalização das startups existentes e ausência de vínculos formais entre elas e os desenvolvedores;

- Inexistência de estudos anteriores que permitam avaliar o estado anterior à criação das primeiras start ups do Campus para avaliação dos impactos promovidos por elas na economia local.

\section{Os determinantes do ecossistema}

A descrição das características iniciais possibilitou o primeiro panorama geral de descrição do ecossistema estudado e verificar a existência de pontos fortes e necessidades de melhorias no mesmo. A descrição do ecossistema de empreendedorismo foi realizada utilizando os determinantes do framework de ANDE (2013): finanças; apoio aos negócios; política; mercados, capital humano; infraestrutura; P\&D e cultura, conforme apresentado a seguir.

\section{Finanças}

No aspecto finanças, foi possível verificar, por meio das entrevistas junto aos desenvolvedores, que esses grupos obtêm recursos financeiros ou materiais para suas atividades de 3 fontes distintas: 
a) Recursos próprios dos desenvolvedores discentes, que representam a maioria dos casos e são um espelho da realidade nacional, conforme BNDES (2018);

b) Recursos obtidos por meio de submissão de projetos em editais de fomento;

c) Recursos obtidos por meio de parcerias e contratos junto a empresas externas de maior porte que investem nos grupos de desenvolvedores.

No ecossistema estudado, não existe disponibilidade local dos determinantes financeiros devido à característica rural da localidade. $\mathrm{O}$ acesso aos determinantes financeiros obtidos por algumas empresas, tais como acesso a financiamento; acesso a capital para investimentos e acesso a angels foram obtidos fora da localidade. Outra forma de acesso a recursos financeiros buscada por todos os desenvolvedores são os editais de fomento e aceleração promovidos no Estado do Rio de Janeiro e em nível nacional.

\section{Apoio aos negócios}

Nos aspectos referentes ao apoio aos negócios, observaram-se, por meio das entrevistas, três fontes de apoio às atividades empreendedoras dos desenvolvedores e em escalas distintas:

a) Campus Engenheiro Paulo de Frontin (CEPF);

b) Governo local;

c) Parceiros comerciais.

\section{i. Apoio do CEPF aos negócios}

O Campus é apontado pelos discentes entrevistados como o principal apoiador aos negócios e ao empreendedorismo local. ocorrendo por meio da disponibilização de infraestrutura física, acesso à internet e principalmente por meio do NPD/SFInJE. Segundo os entrevistados, apesar das limitações financeiras e burocráticas existentes, o CEPF busca de todas as formas possíveis apoiar os empreendedores, seja por viabilizar a participação em eventos da área de tecnologia, seja pelo apoio técnico ao produto ou à gestão das startups. Além disso, a contratação de serviços de mentoria, treinamento e consultoria realizada junto ao SEBRAE torna-se uma das principais formas de apoio aos empreendedores do Campus aliada à infraestrutura física do NPD/SFInJE. O Campus está junto com os desenvolvedores iniciando um processo de amadurecimento no que tange ao apoio aos negócios desses empreendedores, conforme afirma o Diretor Geral do Campus.

\section{ii. Apoio do governo local aos negócios}

A Prefeitura Municipal de Engenheiro Paulo de Frontin é a principal parceira da esfera pública no fomento e apoio ao empreendedorismo da localidade. Por meio de seu poder legislativo e executivo, promove ações junto ao Campus com o objetivo de dar apoio aos negócios dos desenvolvedores do CEPF. Em especial para o setor de empreendedorismo tecnológico, há um projeto no município para a criação de uma aceleradora de negócios, o "FRONTIN HUB". O projeto disponibilizará infraestrutura física e de comunicação em um local no centro da cidade com internet de alta velocidade, prestação de serviços de apoio aos negócios e promoção de networking para as empresas de tecnologia instaladas no HUB. Outra forma de apoio mencionada pelos desenvolvedores proporcionada pelo governo local é a oferta de serviços contábeis de forma gratuita para as startups que possuem tal demanda.

Os entrevistados desenvolvedores reconhecem as ações realizadas pelo governo local para fomentar o empreendedorismo local, porém, destacam a necessidade de intensificação dessas ações, em especial para a formalização das startups criadas no Campus e para melhoria da infraestrutura para os negócios, em especial de comunicação e transportes. Essas melhorias funcionariam tanto para apoiar as startups existentes no ecossistema de empreendedorismo, 
quanto para atrair empresas externas da área de tecnologia e potenciais investidores. Atualmente, não há startup discente formalizada, porém, muitas com a intenção de formalizarse e em processo de formalização.

O governo municipal afirma ter ciência das necessidades de melhorias na infraestrutura e serviços básicos para a manutenção das startups formadas pelos discentes na localidade após o egresso destes da graduação. Com esse objetivo, a Prefeitura busca a finalização da instalação de fibra ótica no município, o que irá melhorar a qualidade da internet em todo o município, da mesma forma afirma estar imbuída em implementar melhorias de infraestrutura necessárias para tornar a cidade um polo tecnológico por meio de apoio político junto às demais esferas políticas estaduais e federais. Como forma de atrair empresas de fora do município e incentivar a criação de empresas de tecnologia, o Legislativo da cidade, em parceria com o CEPF editou uma lei municipal cujo objetivo é dar incentivos fiscais para empresas da área de jogos digitais e tecnologia. A lei municipal é descrita na seção que trata do determinante política.

\section{Parceiros comerciais}

Dentre os parceiros comerciais, estão aqueles pertencentes à esfera privada, eles apoiam os negócios locais por meio de treinamentos, mentorias, consultorias e networking junto aos desenvolvedores locais. Os parceiros apontados pelos entrevistados possuem relacionamento direto com o desenvolvimento gerencial e mercadológico do capital humano que surge no Campus. Dentre os relacionamentos existentes, destacam-se, segundo os entrevistados, o SEBRAE, o RING e o BP Instituto.

\section{- SEBRAE}

O SEBRAE regional do sul fluminense oferece apoio contínuo aos empreendedores do CEPF. Além dos serviços contratados via Campus, em diversas ocasiões, o SEBRAE disponibiliza o transporte para os eventos de forma gratuita e sempre que possível garante a participação dos discentes do Campus em eventos sob sua chancela. A relação de apoio aos empreendedores do Campus pelo SEBRAE está diretamente ligada à sua relação com o CEPF. O SEBRAE foi identificado por todos os desenvolvedores entrevistados como um relacionamento importante e contínuo no apoio aos negócios e desenvolvimento gerencial junto ao ambiente de empreendedorismo existente.

\section{- RING}

O RING, coletivo de empresas de jogos do Rio de Janeiro, apresenta uma relação de longa data com o Campus, apoiando na elaboração do programa de curso à época da implementação da graduação em jogos digitais. Representantes do RING estiveram inclusive presentes na abertura da primeira turma de jogos no Campus e possuem assento previsto no Comitê de Gestão da Incubadora.

Além do relacionamento com o Campus, as empresas do RING ocupam posição de liderança junto às startups discentes do CEPF. De acordo com as entrevistas realizadas, 8 dos 9 desenvolvedores que trabalham em grupo mencionaram estreita relação com o coletivo. Quanto aos desenvolvedores individuais, não houve menção ao RING. O Presidente do coletivo destacou que mantém contínua comunicação junto aos desenvolvedores por meio de um aplicativo de troca de mensagens, fato este ratificado pelos desenvolvedores discentes nas entrevistas.

\section{- BP Instituto}


O BP Instituto é uma instituição com uma longa história voltada para o desenvolvimento de treinamentos na área de informática, gestão e empreendedorismo. Dentre os programas acadêmicos desenvolvidos pelo BP Instituto, estão: Microsoft/Windows, Linux, Oracle, que foram implementados no Brasil. O fundador do BP Instituto apresenta uma história junto ao CEPF iniciando em 2011, desde a implementação do curso técnico em informática para internet por meio da iniciativa de um condomínio de TI localizado no distrito de Morro Azul que manteve suas atividades entre 2011 e 2013.

Atualmente o BP Instituto é um dos atores que têm apoiado as startups do Campus por meio de projeto de aceleração com o objetivo de inseri-las no mercado e promover interação com outras empresas do Estado do Rio de Janeiro em especial aquelas do setor de petróleo e gás. O BP Instituto é um dos parceiros da Prefeitura Municipal na implementação do FRONTIN HUB. Participam do programa junto ao BP Instituto duas startups do Campus, a DESIGN4U (D4U) e a Tinguá Game Studio. A parceria com as startups vislumbra o potencial destas em ampliar o portfólio de produtos para além dos jogos digitais no desenvolvimento de simuladores na área de petróleo e gás.

\section{Política}

No determinante política, observa-se uma mobilização inicial por parte do governo local com o objetivo de dar suporte e atrair empreendimentos de tecnologia para a localidade. Com este objetivo, a gestão do CEPF e o poder legislativo local, elaboraram uma proposta de lei para incentivo à instalação de empresas do setor tecnológico no município. Tal proposta foi aceita pelo legislativo municipal que editou e publicou a Lei municipal 1.122 de 23 de maio de 2013, lei que prevê em seu artigo $1^{\circ}$ a possibilidade de isenção IPTU, ISS, taxa de iluminação pública, e alvará de localização, durante o período inicial de 6 anos, para empresas que se instalarem no município e atendam determinados compromissos empregatícios com munícipes. $\mathrm{O}$ artigo em questão também prevê em seu parágrafo único o benefício de redução de $50 \%$ de ISS, independente da geração mínima de renda, para empresas de tecnologia. Tal lei representa um marco na atração de empresas de tecnologia no município e impacta diretamente nos custos dos negócios de tecnologia criados na localidade.

\section{Mercados}

Devido às características dos produtos das startups do Campus, o determinante mercados é de difícil mensuração. Isso pelo fato dos produtos criados pelos discentes não terem sido comercializados e pela característica do mercado de jogos quanto à inexistência de restrições geográficas para a comercialização de produtos, ocorrendo em um nível global. Verificou-se também o surgimento de um comércio com empresas externas à região para a prestação de serviços e desenvolvimento de jogos digitais.

\section{Capital humano}

O capital humano é o determinante de maior potencial na localidade. O Campus possui a primeira graduação em jogos digitais pública do Brasil e única da área na região. Os discentes do Campus têm se destacado em eventos dos quais participam, seja pelos jogos digitais desenvolvidos, seja pelo perfil empreendedor para a solução de problemas com o uso da tecnologia. Este determinante é visto tanto pelos entrevistados discentes, quanto pelos demais atores externos como de excelência e grande ativo da região.

A existência de capital humano altamente capacitado representa um dos principais incentivos existentes hoje para que os desenvolvedores de jogos, juntamente com suas startups se mantenham na localidade após a conclusão de sua graduação. 
Vale destacar que o capital humano do Campus não se limita aos discentes do curso de graduação, mas também estão inclusos os discentes do curso Técnico em Informática para Internet e do curso de Pós-graduação em Gestão de Projetos e Negócios em TI.

\section{Infraestrutura}

No que tange à infraestrutura na região de Morro Azul e Sacra Família, todos os 16 desenvolvedores entrevistados destacam dificuldades diante da atual infraestrutura de telecomunicação e transporte local. Os empreendedores relataram a dificuldade em obter serviços de telecomunicação e internet com qualidade suficiente para a realização de atividades e para comunicação com possíveis investidores e parceiros. Tal situação é mitigada, no momento em que os desenvolvedores utilizam a infraestrutura de telecomunicação do Campus, atualmente fornecida diretamente da (Rede Nacional de Ensino e Pesquisa) em um link de $80 \mathrm{Mb}$.

Outro aspecto que necessita de melhorias é a infraestrutura de transporte público na localidade, que possui apenas duas empresas em atividade com horários esparsos e coincidentes entre as duas. Os entrevistados também destacam valores elevados para um deslocamento de 3 km de distância entre os distritos de Morro Azul, Sacra Família e o Campus.

No que tange aos serviços básicos de eletricidade e água, os 15 desenvolvedores entrevistados foram unânimes quanto aos aspectos referentes a suas condições. No que se refere aos serviços de fornecimento de água, não foram relatados problemas, provavelmente pelo fato de os distritos de Morro Azul e Sacra Família estarem localizados em meio à Mata Atlântica sobre lençóis aquíferos. Quanto à energia elétrica, foram destacados frequentes "picos" de energia.

Diante das demandas referentes à infraestrutura local, observa-se a mobilização dos atores envolvidos no ecossistema de empreendedorismo em formação no intuito de contornar os déficits apresentados. Segundo a direção do Campus, há um processo licitatório em curso para a concessão de espaço para a implementação de um restaurante com previsão de prestação de serviços no ano de 2019. Da mesma forma, há um projeto na busca de melhorias da rede lógica do Campus por meio de reestruturação e ampliação de sua rede de dados cabeada.

Foram observados aspectos críticos na infraestrutura local e que demandam investimentos por parte dos stakeholders da localidade, em especial do governo local e do Campus. Diante das necessidades de melhorias na infraestrutura existentes, esses atores apresentam ações com efeitos no curto e médio prazo, que serão capazes de minimizar os problemas apresentados, se colocadas em prática.

Segundo os discentes, apesar da necessidade de melhorias na infraestrutura, pode-se observar uma melhoria gradual da infraestrutura local quando comparada com aquela de 5 anos atrás, dentro e fora do Campus. Assim sendo, os desenvolvedores apresentam-se, sem exceções, otimistas quanto às projeções de melhorias para a localidade visto que os stakeholders têm ao longo do tempo se mobilizado de forma eficaz para desenvolver o ambiente de empreendedorismo local.

\section{Pesquisa e Desenvolvimento (P\&D)}

Nos aspectos referentes a $\mathrm{P} \& \mathrm{D}$, foram identificados 3 projetos em desenvolvimento no Campus, 2 deles voltados à área de ensino e 1 voltado à inovação em jogos. Verificou-se que a pesquisa no Campus se apresenta também em um estágio inicial de desenvolvimento pelo fato de muitos projetos existentes no Campus possuírem caráter extensionista não voltados à pesquisa. 
Atualmente o CEPF possui um projeto de pesquisa na área de balanceamento de dinâmico de jogos. Este projeto está em desenvolvimento no Campus desde 2016 e conta com 3 bolsistas, sendo que 2 bolsas são custeadas pelo CNPQ e 1 custeada com recursos do Campus. Hoje, todas as pesquisas voltadas à área de computação desenvolvidas no Campus são realizadas com unidade de processamento gráfico da NVIDIA por meio de uma parceria entre as instituições. O Coordenador da COPI do Campus também destaca a existência de potenciais parceiras de pesquisa via acordo de cooperação e convênios com a Universidade Federal Fluminense (UFF), Universidade Federal do Rio de Janeiro (UFRJ), Instituto Nacional de Pesquisa Aplicada (INPA) e PUC- Rio.

Outro projeto que merece destaque é o jogo voltado para o ensino chamado "Dia a Dia com a Turma do Ifinho" a pesquisa é direcionada para aprendizagem de crianças com transtornos de comportamento e aprendizagem, tais como dislexia, TDAH (Transtorno do Déficit de Atenção com Hiperatividade) e autismo. O jogo busca, por meio das situações vividas pelo personagem chamado Ifinho, auxiliar crianças com transtornos de aprendizagem. O jogo desenvolvido já foi aplicado na rede pública de ensino da localidade junto a crianças com este perfil.

Um terceiro projeto de pesquisa que merece destaque é um jogo educativo, vinculado à disciplina de língua inglesa com foco no ensino do idioma para alunos do curso técnico em informática para internet. O objetivo é desenvolver um modelo de jogo educativo para o ensino do inglês instrumental voltado para as demandas da área de tecnologia.

Espera-se que com os resultados de algumas das ações que se iniciam no Campus na área de pesquisa seja possível, no futuro, o amadurecimento da área de P\&D, com mesma intensidade que o empreendedorismo acadêmico, para produzir e levar à sociedade inovações desenvolvidas pelo seu capital intelectual. Atualmente observa-se que empreendedorismo e P\&D não caminham na mesma velocidade no ecossistema que surge.

\section{Cultura}

A cultura empreendedora representa um ponto forte da localidade, os atores que possuem relacionamento com o CEPF buscam fomentar direta ou indiretamente $\mathrm{o}$ empreendedorismo vindo dos alunos. Neste sentido, o Campus tem obtido sucesso no fomento à cultura empreendedora por meio das ações pedagógicas e não-pedagógicas de fomento ao empreendedorismo acadêmico. Esta cultura é potencializada pela concentração de desenvolvedores com perfil empreendedor e pelo fato de esses desenvolvedores viverem em repúblicas e imóveis alugados nos distritos de Morro Azul e Sacra Família. Todos os entrevistados são moradores do município ou estão vivendo fora de suas cidades natais em repúblicas nos distritos da localidade do CEPF.

Observa-se que os desenvolvedores se encontram motivados a empreender e promover a cultura empreendedora junto aos seus pares, um exemplo desta motivação é o Arquipélago, uma iniciativa dos empreendedores e desenvolvedores discentes em fortalecer a cultura empreendedora junto aos demais alunos. Diferentemente da Yuna, o Arquipélago possui caráter formal. A iniciativa começou a ser organizada no início de 2018 e promove eventos como palestras e debates na área de jogos com o objetivo de promover a troca de experiência e de informações para os participantes. Atualmente, o Arquipélago é composto por desenvolvedores das startups mais consolidados no CEPF e aqueles desenvolvedores mais motivados em promover o empreendedorismo junto à comunidade acadêmica de discentes. Em geral, os eventos promovidos pelo grupo ocorrem no CEPF, que disponibiliza a infraestrutura necessária 
Além do Arquipélago, há ainda uma mobilização por parte das discentes do Campus. A comunidade acadêmica da graduação em jogos digitais conta hoje com uma desproporcionalidade entre discentes do sexo masculino e feminino, sendo estas últimas uma minoria considerável. Diante deste quadro, as discentes do sexo feminino têm se mobilizado no intuito de incentivar o desenvolvimento e disseminação de conhecimentos na área de programação junto às discentes do Campus por meio do grupo Devgirls, um grupo de desenvolvedoras criado por iniciativa das discentes do CEPF, o nome do grupo remete à Developer Girls (meninas desenvolvedoras), que tem como objetivo unir e fortalecer as discentes do CEPF, que atualmente são minoria no curso de graduação em jogos. Hoje, há 30 discentes do sexo feminino em um total de 159 alunos matriculados no curso de graduação, representando pouco mais de $18 \%$ dos discentes. O grupo surgiu por iniciativa de algumas alunas do curso de graduação que, pelo fato de serem minoria no curso, em algumas ocasiões, sentem-se mais retraídas em meio a um ambiente majoritariamente masculino.

A presença de uma cultura empreendedora consolidada dentro do CEPF potencializa e polariza relacionamentos do Campus e dos desenvolvedores com atores externos ao Campus. Esses atores iniciam uma aproximação com o empreendedorismo acadêmico da localidade, a exemplo do RING, BP Instituto, Governo local, SEBRAE e outros potenciais investidores. Esses relacionamentos, apesar de estarem em fase inicial, promovem o fortalecimento da cultura empreendedora e do apoio aos negócios locais. Verificou-se que no ecossistema de empreendedorismo emergente na localidade a cultura empreendedora, capital humano e política representam pontos fortes a serem destacados. Porém, aspectos como infraestrutura representam atualmente os maiores limitadores para o desenvolvimento do ecossistema de empreendedorismo em formação. Ratificando a incipiência do ecossistema, investimentos e ações na área de apoio aos negócios e P\&D se encontram em estágio de implementação por parte de atores deste ambiente.

Neste contexto, o ecossistema de empreendedorismo do CEPF inicia uma trajetória promissora ao dar continuidade ao movimento de aproximação entre o empreendedorismo acadêmico e o mercado de tecnologia por meio de seus outputs.

\section{Considerações finais}

O esforço da pesquisa permitiu o levantamento das ações de fomento ao empreendedorismo acadêmico do CEPF iniciadas em 2013 e realizadas em caráter contínuo, com a criação do curso de graduação em jogos digitais. Essas ações possuem relação direta com o surgimento de um ambiente com aspectos de um ecossistema de empreendedorismo incipiente na localidade predominantemente rural na qual o Campus está localizado. Este ecossistema, centrado no empreendedorismo acadêmico do CEPF, está em um estágio inicial de formação, direcionado a produtos e serviços tecnológicos, tendo destaque a área de jogos digitais. No ambiente estudado, verificou-se a existência de estratégias de cooperação e competição cuja dinâmica indica um ecossistema em um estágio de nascimento.

Ao atuar como fomentador de empreendedorismo, o Campus inicia uma série de relacionamentos com atores externos que atuam como potencializadores do empreendedorismo acadêmico e que permeiam as micro e macrocirculações da Hélice Tríplice. No ambiente estudado, destacam-se os relacionamentos trilaterais entre as esferas que compõem o ecossistema, a exemplo das relações entre CEPF, SEBRAE, Governo Local, Startups e desenvolvedores do CEPF, RING e BP Instituto.

Quanto aos aspectos observados do ecossistema local, verificou-se que este possui aspectos positivos no que tange à existência de uma cultura empreendedora consolidada na 
localidade; capital humano de excelência e uma política voltada para atração e incentivos a empresas de tecnologia. Pontos relacionados à infraestrutura apresentam-se como limitadores para o crescimento do ecossistema estudado e representam a principal preocupação de seus atores. Porém, o fato de haver consenso desta fragilidade por parte dos envolvidos gera a expectativa de ações de curto prazo para melhorias na área.

$\mathrm{O}$ aspecto do mercado local não representa, inicialmente, um limitador para o crescimento desse ecossistema dadas as características do mercado de tecnologia e a inexistência de barreiras geográficas para comercialização de seus outputs. O mesmo pode ser afirmado no quesito finanças, que atualmente é obtido externamente à localidade do Campus por meio da participação em editais de fomento à tecnologia e empreendedorismo ou pelo networking realizado com o mercado. Acredita-se que esses dois determinantes se tornarão mais presentes no ecossistema ao passo em que este continue seu processo de maturação e se torne atrativo para o mercado e para investidores.

Ainda referente à incipiência do ecossistema, verificou-se que aspectos como apoio aos negócios e P\&D se encontram em um estágio inicial de maturação por parte dos atores da esfera governo e universidade, em especial no apoio aos empreendimentos que surgem na academia, o que também acaba por promover a consolidação da cultura de promoção da empreendedora na localidade. Apesar do estágio em que se encontram, destacam-se iniciativas promissoras em P\&D por meio das pesquisas iniciadas no CEPF. Da mesma forma, por meio de sua rede de relacionamentos, o ecossistema apresenta investimentos iniciais em serviços de apoio aos negócios por meio de serviços de treinamento gerencial e consultorias.

Para o desenvolvimento contínuo do ecossistema de empreendedorismo é necessário alinhamento de esforços entre os stakeholders da localidade. Esses esforços devem concentrase em aspectos como a infraestrutura local, cujo estado atual pode, em certo grau, prejudicar aspectos avaliados como positivos do ecossistema de empreendedorismo que surge e eventualmente provocar a fuga de capital humano e afastamento de potenciais investidores da localidade. Assim, foi possível constatar ações sinalizadas pelos atores locais no sentido de sanar os problemas de infraestrutura existentes.

Acredita-se que a presente pesquisa seja capaz de auxiliar na compreensão do papel do CEPF no fomento ao empreendedorismo acadêmico local e sua relação com o surgimento de um ambiente com aspectos de um ecossistema de empreendedorismo incipiente na localidade predominantemente rural do Campus.

Espera-se também que a presente pesquisa possa orientar futuros estudos acerca do ecossistema de empreendedorismo tecnológico do Campus Engenheiro Paulo de Frontin e que futuros pesquisadores tenham um panorama inicial desse ecossistema tecnológico emergente.

Para futuros estudos, propõe-se uma pesquisa direcionada para a trajetória das startups criadas, que consigam manter seu crescimento e eventualmente sucesso na localidade. Outra proposta é que em um período de médio a longo prazo, ocorrendo maturação do ecossistema, seja realizada uma análise do ecossistema de empreendedorismo local, aprofundando o estudo dos determinantes do ecossistema de empreendedorismo, bem como da performance empreendedora e impactos do mesmo na localidade, conforme metodologia apresentada por ANDE (2013).

O ecossistema de empreendedorismo tecnológico que emerge na localidade do Campus Engenheiro Paulo de Frontin representa um marco para o desenvolvimento da localidade. Ainda que incipiente, este ecossistema representa as potencialidades do relacionamento Universidade - Indústria - Governo como um determinante na mudança da localidade onde esta interação ocorre, bem como do papel da universidade como ator central na promoção do 
empreendedorismo de base tecnológica. Verifica-se o papel do Campus Engenheiro Paulo de Frontin como centro do empreendedorismo tecnológico local e que, por meio dos empreendimentos criados na acadêmica, inicia um processo de articulação com atores locais que ao longo deste relacionamento têm promovido o desenvolvimento de um ambiente de empreendedorismo local com a potencialidade de transformações na região em que está inserida.

Apesar das fragilidades existentes, a comunidade empreendedora encontra-se motivada a fazer da região um polo de tecnologia e empreendedorismo com foco na área de jogos digitais. Esta motivação é estendida aos demais atores que buscam, por meio de parcerias, atuar no desenvolvimento deste ecossistema empreendedor. Esta motivação, aliada aos resultados alcançados pelos produtos desenvolvidos pelos empreendedores discentes destacam a potencialidade do ecossistema de empreendedorismo emergente em se tornar um promotor de mudanças na economia da localidade Rural estudada desde que cada um dos atores envolvidos assuma seu papel e responsabilidade no ecossistema.

\section{Referências}

Acs Z. J., Szerb L., \& Lloyd, A. (2017) Enhancing Entrepreneurial Ecosystems: A GEI Approach to Entrepreneurship Policy. In: Global Entrepreneurship and Development Index 2017. Springerb Briefs in Economics. Springer, Cham.

Alves, A. C., Fischer, B., \& Schaeffer, P. R. (2019). Determinants of Student Entrepreneurship. An Assessment on Higher Education Institutions in Brazil. Innovation and Management Review, 16(2), 96-117.

ANDE. Entrepreneurial Ecosystem Diagnostic Toolkit (2013). Aspen Network of Development Entrepreneurs. Pp. 1-32.

Bezanilla, M. J., García-Olalla, A., Paños-Castro, J., \& Arruti, A. (2020). Developing the Entrepreneurial University: Factors of Influence. Sustainability, 12, 842.

BNDES - BANCO NACIONAL DO DESENVOLVIMENTO. (2018). $<$ https://www.bndes.gov.br /wps/portal/site/home/conhecimento/noticias/noticia/jogosdigitais-brasil-infografico $>$. Acessado em 25 de junho de 2018.

Bueno, N. (2017). Instituições e políticas para o desenvolvimento tecnológico regional na nova economia do conhecimento: uma análise para o Brasil utilizando o modelo da tripla hélice. Revista Gestão \&Tecnologia, 17(4), 13-42. $<$ https://doi.org/10.20397/2177-6652/2017.v17i4.1250>.

Cantamessa, M. (2016). I3P as university business incubator - A dual mission in technology transfer and start-up ecosystem development. In De Cleyn S. and G. Festel (eds.), Academic Spin-offs and Technology Transfer in Europe. Edward Elgar. London.

Chais, C., Castorena, D. G., Welchen, V., Mukendi, J. T., Maciel, J. V., Ganzer, P. P., Matte, J., \& Olea, P. M. (2019). Análise da Opinião de Acadêmicos sobre Universidades Empreendedoras: Uma Comparação entre Brasil e México. Revista Economia \& Gestão, 19(54), 133-153.

Damnjanovic, V., Jovanovic, M., \& Rakicevic, J. (2019). Putting Triple Helix into Action: Evidence from Serbia. The European Triple Helix Congress (ETHAC2019) Responsible Innovation \& Entrepreneurship. 
Díez-vial, I. \& Montoro-Sánchez, A. (2016). How knowledge links with universities may foster innovation: The case of a science park. Technovation. Pp. 41-52.

Eisenhardt, K. M. (1989). Building theories from case study research. Academy of Management Review, v.14, n.4, p. 532-550.

Etzkowitz, H. (2008). The Triple Helix: University-Industry-Government Innovation in Action. Routledge, London.

, \& Leydesdorff, L. (2000). The dynamics of innovation: From National Systems and "mode 2" to a Triple Helix of university-industry-government relations. Research Policy, 29(2).

\& Leydesdorff, L. (1997). Universities and the global knowledge economy: a triple helix of university-industry-government relations / edited by Henry Etzkowitz e Loet Leydesdorff. Continuum, London. Science, Technology and the International Political Economy Series, $184 \mathrm{p}$.

empreendedorismo universidade-indústria, C. (2017). Hélice Tríplice: inovação 48.<https://dx.doi.org/10.1590/s0103-40142017.3190003>.

Feld, B. (2012). Startup communities: Building an entrepreneurial ecosystem in your city. Hoboken, NJ: John Wiley \& Sons.

Gamonar, F.; Jannuzzi, G., \& Munaro, J. (2017). Disrup Talks: Carreira, empreendedorismo e inovação em uma época de mudanças rápidas. São Paulo. ReflexãoEditora.

Hernández, C., \& González, D. (2017). Study of the start-up ecosystem in Lima, Peru: Analysis of interorganizational networks. Journal of Technology Management and Innovation, 12(1).

Iansiti, M., \& Levien, R. (2004). The Keystone Advantage: What the new dynamics of business ecosystems mean for strategy, innovation, and sustainability. Harvard Business School Publishing Corporation.

Lorentz, M. H. N. (2015). O Comportamento Empreendedor de Diretores da UFSM e sua percepção quanto à Universidade Empreendedora. Dissertação apresentada ao Curso de Mestrado Profissional em Gestão de Organizações Públicas do Programa de PósGraduação em Administração.

Lundvall, B. A. (2016). The Learning Economy and the Economics of Hope. Research Series 31.

Meyer, M. (2003). Academic entrepreneurs or entrepreneurial academics? Researchbased ventures and public support mechanisms. R and D Management, 33(2).

Miller, D. J., \& ACS, Z. J. (2018). The Campus as entrepreneurial ecosystem: the University of Chicago. Small Business Economics, 49(1). 2017. Disponível em: $<$ https://doi.org/10.1007/ s11187-017-9868-4>. Acesso em: 10 de janeiro de 2018.

Mitleton-Kelly, E. (2003) Ten Principles of Complexity and Enabling Infrastructures. Program Manager. In: Mitleton-Kelly, E.; Complex Systems and 
Evolutionary Perspectives of Organizations: the Application of Complexity Theory to Organizations. Elsevier, 23-50.

Moore, J. F. (1993). Predators and prey: a new ecology of competition. Harvard Business Review, 71(3), 75-86.

Ramos, M. C. L., Campos, R. A., May, P. R., Boiani, E., Mafra, S. M., \& Cruz, A. G. (2017). Universidade/empresa/governo o tripé da inovação: Estudo de Casos nas fundações de apoio da UFSC. Colóquio Internacional de Gestão Universitária. Universidade, desenvolvimento e futuro na sociedade do conhecimento. Argentina.

Renault, T. B., Fonseca, M. V. A., Cunha, R. M., \& Carvalho, R. S. (2010). Empreendedorismo Acadêmico na COPPE/UFRJ: Reflexões Sobre Empresas Criadas com a Participação de Professores. In EnANPAD, 1-17.

Rosa, L. (2014). ITSM: um caso de sucesso do Modelo Tríplice Hélice. Revista de Administração. UFSM, Santa Maria, v. 7, Edição Especial, 55-69.

Ruddin, L. P. (2006) You can generalize stupid! Social scientists, Bent Flyvbjerg, and case study methodology. Qualitative Inquiry, 12(4), 797-812.

Santos, E., \& Benneworth, P. (2019). Interação Universidade-Empresa: Características identificadas na literatura e a colaboração regional da Universidade de Twente. Revista de Administração, Sociedade e Inovação, RASI, Volta Redonda/RJ, 5(2), $115-143$.

Sarpong, D.; Abdrazak, A.; Alexander, E., \& Meissner, E. (2017). Organizing practices of university, industry and government that facilitate (or impede) the transition to a hybrid triple helix model of innovation. Technological Forecasting and Social Change.

Siegel, D., \& Wright, M. (2015). "Academic entrepreneurship: time for a rethink?”, British Journal of Management, 26(4), 582-595.

Silva, F. G., Ribeiro, J. A., \& Barros, F. M. R. (2019). Mapeamento da atuação dos Núcleos de Inovação Tecnológica dos Institutos Federais de Educação, Ciência e Tecnologia dos estados de Minas Gerais e Espírito Santo. Revista de Administração, Sociedade e Inovação, RASI, 5(2), 180-197.

Van Rijnsoever, F. J. (2020). Meeting, mating, and intermediating: How incubators can overcome weak network problems in entrepreneurial ecosystems, Research Policy, 49(1),ISSN 0048-7333.

Vergara, S. C. (2012). Métodos de Coleta de Dados no Campo. São Paulo: Atlas, $2^{\mathrm{a}}$ edição.

Wright, M., Siegel, D.S. \& Mustar, P. (2017). An emerging ecosystem for student start-ups. The Journal of Technology Transfer, 42(4),909-922. Bookman.

Yin, R. K. (2005). Estudo de caso: planejamento e métodos. $3^{\text {a }}$ Edição. Porto Alegre: 